\title{
Granuloma annulare: relationship to diabetes mellitus, thyroid disorders and tuberculin skin test
}

\author{
Pedram Alirezaei \\ Mahmood Farshchian \\ Department of Dermatology, Psoriasis \\ Research Center, Farshchian Hospital, \\ Hamadan University of Medical \\ Sciences, Hamadan, Iran
}

This article was published in the following Dove Press journal:

Clinical, Cosmetic and Investigational Dermatology

26 April 2017

Number of times this article has been viewed

Background: Granuloma annulare is a benign inflammatory disease of the skin. The etiology and pathogenesis of the disease are not yet determined, but some authors have proposed that it might be associated with a variety of underlying conditions such as thyroid disorders, diabetes mellitus and positive tuberculin skin test.

Objective: This study was conducted to find the probable relationship between granuloma annulare and diabetes mellitus, thyroid disorders and positive tuberculin skin test.

Patients and methods: A total of 28 patients with granuloma annulare were recruited from our dermatology outpatient clinic, and data on sex, age and distribution of granuloma annulare lesions were collected. Forty-one age- and sex-matched apparently healthy volunteers serving as controls were also included. Thyroid stimulating hormone (TSH), fasting blood sugar (FBS) and tuberculin skin tests were performed for both groups.

Results: Mean serum level of FBS in the patient group was significantly higher than the mean serum level of FBS in the control group $(110.60 \pm 46.31 \mathrm{mg} / \mathrm{dL}$ versus $88.39 \pm 10.58 \mathrm{mg} / \mathrm{dL}$, respectively, $p=0.004$ ). Mean serum level of TSH in the patient group was $3.43 \pm 2.73 \mathrm{mIU} / \mathrm{L}$, which was not significantly different from the mean serum level of TSH in the control group $(3.26 \pm 2.11 \mathrm{mIU} / \mathrm{L}, p=0.772)$. Four individuals in the patient group and only 1 in the control group had a positive tuberculin skin test.

Conclusion: Granuloma annulare patients are better to be assessed for diabetes mellitus, but the relationship between this skin disease and thyroid disorders or tuberculin skin test still needs to be investigated.

Keywords: granuloma annulare, thyroid, diabetes mellitus, tuberculin skin test

\section{Introduction}

Granuloma annulare (GA) is a relatively common idiopathic disorder of the dermis and subcutaneous tissue with an estimated incidence of $0.1-0.4 \%{ }^{1}$ The lesions typically appear as papules and plaques with annular margins most commonly on dorsal surfaces of hands, arms and feet. ${ }^{2}$ The disease affects all age groups, and women are affected more commonly than men. Various clinical forms of GA, including localized, generalized, subcutaneous, patch and perforating types, have been described. Localized variant is probably the most common form of GA, but the disease can sometimes become disseminated in larger areas of skin. Generalized GA is defined by the simultaneous involvement of trunk and upper or lower extremities. Some authors believe that extensive involvement of extremities without involvement of trunk can also be classified as generalized form of the disease. ${ }^{2,3}$ Subcutaneous GA is characterized

Correspondence: Pedram Alirezaei Psoriasis Research Center, Farshchian Hospital, Mirzadeh Eshghi Street,

Hamadan, Iran

Tel/fax +988138272154

Email prc@umsha.ac.ir 
by subcutaneous nodules that are often found on lower extremities of children. In patch GA, lesions are flat rather than being papular and sometimes may cover large areas of skin. Perforating GA is defined clinically by umbilicated papules that may have central crust. ${ }^{4-7}$ The natural history of GA is quite variable, but it has a tendency to spontaneous involution in a high proportion of patients. ${ }^{8}$ Diagnosis of GA is based on clinical and histopathological examinations. In histopathological studies, the classic presentation of GA is a palisading granuloma characterized by histiocytes and epithelioid cells surrounding a central zone of altered collagen. In well-developed lesions, there is mucin deposition within the foci of altered collagen. ${ }^{3}$

GA has been associated with a variety of comorbidities, including diabetes mellitus, thyroid disorders, dyslipidemia, underlying malignancies and tuberculosis. ${ }^{9-14}$ There are also reports suggesting the appearance of GA following bacillus Calmette-Guérin vaccination. ${ }^{15,16}$ Although several underlying conditions have been linked to GA, little data from controlled studies are available to validate these associations. Even the relationship between GA and diabetes mellitus (which is probably the most reported comorbidity to occur in GA-affected patients) is still controversial.

The aim of this study was to examine the relationship between GA and thyroid disorders, diabetes mellitus and positive tuberculin skin test.

\section{Patients and methods}

This case-control study was conducted on 28 consecutive GA patients presenting to the Department of Dermatology, Farshchian Hospital, Hamadan, Iran, between January 2013 and June 2014 as the patient group and 41 age- and sexmatched apparently healthy volunteers as the control group. All patients with clinical diagnosis of GA underwent skin biopsy for histopathological examination. After the confirmation of diagnosis, a total of 28 patients were recruited. The ethics committee of Hamadan University of Medical Sciences approved the study protocol, and informed consent was obtained from all participants. The study protocol was also in accordance with the 1975 Declaration of Helsinki (revised in 2008). Demographic and clinical data such as sex, age and distribution of lesions were recorded. Laboratory tests were performed in all participants (patients and control subjects), including serum thyroid stimulating hormone (TSH), fasting blood sugar (FBS) and tuberculin skin tests.

Serum TSH was measured using electrochemiluminescence (ECL) assay (Roche Diagnostics Limited, Rotkreuz,
Switzerland). According to the measurement kit, the normal range for TSH was $0.4-6.21 \mathrm{mIU} / \mathrm{L}$.

FBS was measured using Pars Azmoon kits (Tehran, Iran). Measurements were assayed on an autoanalyzer (Mindray BS300, Shenzhen, China). Normal FBS was defined as a value of $<100 \mathrm{mg} / \mathrm{dL}$ after 8 hours of fasting, impaired fasting glucose (IFG) as 100 to $<126 \mathrm{mg} / \mathrm{dL}$ and diabetes mellitus as $\geq 126 \mathrm{mg} / \mathrm{dL}$.

Tuberculin skin test was performed using the Mantoux method. In this method, 5 units of PPD $(0.1 \mathrm{ml})$ are injected by a 27 -gauge needle intradermally in the volar aspect of forearm, and the diameter of induration is read after 48-72 hours. Since Iran is a high prevalence country for tuberculosis and our study subjects had no known immunosuppression or recent contact with tuberculosis, an induration higher than $10 \mathrm{~mm}$ in diameter was considered positive. The results were analyzed using SPSS 13.0 software (SPSS Inc., Chicago, IL, USA) for windows.

\section{Results}

Of 28 patients, 24 were female and 4 were male. Of 41 controls, 35 were female and 6 were male. There was no statistically significant difference between cases and controls regarding sex (Fisher's exact test: $p=0.626$ ). The average age of female and male patients was 53.41 \pm 15.2 and $23 \pm 20.9$ years, respectively. The average age of female and male controls was $55.12 \pm 14.1$ and $24 \pm 20.3$ years, respectively. There was no statistically significant difference between cases and controls regarding age (independent samples $t$-test: $p=0.732$ ).

In this study, 20 patients $(71.42 \%)$ presented the localized variant of GA, whereas generalized variant was observed in 7 patients $(25 \%)$ and only 1 patient had the subcutaneous form (3.57\%). Perforating variant of GA was not seen in any of the patients. The most prevalent sites of involvement were upper extremities (88\%), lower extremities (8\%) and trunk (4\%).

Mean serum level of FBS in the patient group was significantly higher than mean serum level of FBS in the control group $(110.60 \pm 46.31 \mathrm{mg} / \mathrm{dL}$ versus $88.39 \pm 10.58 \mathrm{mg} / \mathrm{dL}$, respectively, independent samples $t$-test: $p=0.004)$. Six out of 28 patients with GA $(21.4 \%)$ and 5 out of 41 individuals in the control group (12.1\%) had a fasting blood glucose level $>126 \mathrm{mg} / \mathrm{dL}$. All these hyperglycemic individuals in both groups subsequently proved to have diabetes mellitus according to repeated high fasting blood glucose levels. No case of IFG was found in either groups.

Mean serum level of TSH in the patient group was $3.43 \pm 2.73 \mathrm{mIU} / \mathrm{L}$, which was not significantly differ- 
ent from mean serum level of TSH in the control group (3.26 $\pm 2.11 \mathrm{mIU} / \mathrm{L}$, independent samples $t$-test: $p=0.772$ ). According to TSH reference value (0.4-6.21 mIU/L), 1 patient with GA had lower than normal and 3 patients had higher than normal serum TSH levels. The patient with low TSH level was subsequently proved to be hyperthyroid according to high free thyroxine (FT4) level (5.8 ng/dL). The 3 patients whose TSH levels were elevated proved to have subclinical hypothyroidism according to normal values of FT4. Five out of 41 individuals in the control group (12.1\%) had TSH levels higher than normal, but no lower than normal TSH levels were detected in this group. These 5 control subjects subsequently proved to have subclinical hypothyroidism according to normal values of FT4. The patient group had more positive tuberculin skin tests than the control group, but statistical analysis could not be performed because of the very small number of positive tests in both groups (4 versus 1).

\section{Discussion}

GA is a benign, granulomatous dermatosis. It is characterized by collagen degeneration, palisaded or interstitial histiocytic infiltration and mucin deposition histologically. ${ }^{17}$ Although several hypotheses have been proposed to explain the etiopathogenesis of GA, the exact cause of the disease is not yet recognized. Many precipitating factors such as subcutaneous injection for desensitization, ${ }^{18}$ Octopus bite, ${ }^{19}$ bacillus Calmette-Guérin vaccination, ${ }^{15}$ mesotherapy ${ }^{20}$ and ultraviolet light exposure ${ }^{21}$ have been reported but never confirmed by controlled studies. Recent studies have pointed to a delayed-type hypersensitivity reaction to an unknown antigen as the probable mechanism underlying the development of GA lesions. ${ }^{22,23}$

Associations of GA with systemic diseases have been described but not yet consistently confirmed. Although there are multiple reports of GA occurring in the setting of diabetes mellitus, dyslipidemia, thyroid disorders, malignancies and infections, little data are available from large controlled studies. $^{24}$

In accordance with other studies, we observed a female predominance of GA (the female to male ratio was $6: 1$ ). ${ }^{2,3}$ On the basis of available data, the prevalence of GA in the general population is estimated to be $0.1-0.4 \%$, which also shows predominance for women. ${ }^{7}$ In this study, the average age of male patients was significantly lower than females. Previous studies have revealed that more than two-third of patients with GA are in their first 3 decades of life. ${ }^{8}$ In our study, the male patients showed the same pattern, whereas females were mostly in their fourth to fifth decades of life.
In accordance with previous studies, we found upper and lower extremities the most prevalent sites of involvement ( $88 \%$ and $8 \%$, respectively). ${ }^{2,6}$ We also found the localized variant of GA the most prevalent clinical type (71.42\%), whereas generalized and subcutaneous variants were less prevalent ( $25 \%$ and $3.57 \%$, respectively). Other studies had previously revealed that the localized variant is far more common than the generalized or perforating type. ${ }^{11,25}$

We demonstrated that the mean level of FBS is significantly higher in the patient group than in the control group $(p=0.004)$. In a study conducted by Studer et $a 1,{ }^{25} 12 \%$ of 84 patients with GA (localized or generalized) were diabetic while the prevalence of diabetes mellitus among the regional population was estimated to be $5 \%$. Studer et $\mathrm{al}^{25}$ also demonstrated that diabetic patients were more frequently involved by the chronic relapsing form of GA than nondiabetic patients. Muhlemann and Williams ${ }^{9}$ also found a strong association between localized GA and diabetes mellitus in a large population study. Kidd et $\mathrm{al}^{26}$ demonstrated that glucose tolerance may be reduced and insulin levels increased in patients with GA. In spite of these findings, the relationship between GA and diabetes mellitus is still a matter of debate. Nebesio et $\mathrm{al}^{27}$ did not find any significant relationship between these 2 conditions, and Dicken et $\mathrm{al}^{28}$ also failed to show this association. Nonetheless, simultaneous appearance of necrobiosis lipoidica, GA and diabetes mellitus in a same patient has been reported previously. ${ }^{29,30}$ Davison et $\mathrm{al}^{30}$ proposed that GA is in fact associated with diabetes mellitus, but this association may be masked because of not recognizing these 2 conditions at the same time.

The present study revealed that the mean level of TSH was not significantly different between patients and controls. In the study conducted by Vázquez-López et al, ${ }^{10}$ autoimmune thyroiditis was significantly more common in adult women with localized GA than in the control group. In another study carried out by Dabski and Winkelmann ${ }^{3}$ on 100 patients with generalized GA, thyroid disorder was found in 13 patients (hypothyroidism in 6, Graves' disease in 3, thyroiditis in 3 , and thyroid adenoma in 1). Findings of our study and other studies mentioned earlier indicate that the relationship between GA and thyroid disorder cannot be definitely confirmed or denied. We observed that tuberculin skin test was more commonly positive in GA patients compared to controls. Winkelmann ${ }^{14}$ has previously reported a case of chronic inadequately treated tuberculosis with GA-like lesions. Kakurai et $\mathrm{al}^{16}$ have also reported GA in a 12 -year-old Japanese boy 5 days after bacillus Calmette-Guérin vaccination. Mycobacterium in fact may play a role in induction of 
a delayed-type hypersensitivity reaction, which subsequently leads to granuloma formation. Mycobacterium antigen can trigger a relatively small population of $\mathrm{T}$ cells, which are capable of recruiting a larger number of T cells nonspecifically, leading to the formation of GA lesions. However, a pathogenic association cannot be claimed between GA and bacillus Calmette-Guérin vaccination or tuberculin skin test based on a few case reports, and since there are no similar controlled studies focusing on the relationship between positive tuberculin skin test and GA, our findings encourage further studies to be performed on this issue.

\section{Conclusion}

This study indicates that GA may be associated with diabetes mellitus; however, because of the small number of positive tuberculin skin tests, the relationship between GA and this test could not be confirmed. Regarding thyroid disorders, again small number of patients who had the abnormality did not permit us to confirm any relationship. Definitely, further large studies are needed to examine these associations.

\section{Author contributions}

Pedram Alirezaei helped in the analysis and interpretation of data, writing and revising the article and its final approval. Mahmood Farshchian helped in designing the project, writing and revising the article and its final approval.

\section{Disclosure}

The authors report no conflicts of interest in this work.

\section{References}

1. Muhlbauer JE. Granuloma annulare. J Am Acad Dermatol. 1980; 3(3):217-230.

2. Cyr PR. Diagnosis and management of granuloma annulare. Am Fam Physician. 2006;74(10):1729-1734.

3. Dabski K, Winkelmann RK. Generalized granuloma annulare: clinical and laboratory findings in 100 patients. J Am Acad Dermatol. 1989;20(1):39-47.

4. Dahl MV. Speculations on the pathogenesis of granuloma annulare. Australas J Dermatol. 1985;26(2):49-57.

5. Mutasim DF, Bridges AG. Patch granuloma annulare: clinicopathologic study of 6 patients. J Am Acad Dermatol. 2000;42(3):417-421.

6. Smith M, Downie J, DiCostanzo D. Granuloma annulare. Int J Dermatol. 1997;36(5):326-333.

7. Thornsberry LA, English JC. Etiology, diagnosis, and therapeutic management of granuloma annulare: an update. Am J Clin Dermatol. 2013;14(4):279-290.

8. Wells RS, Smith MA. The natural history of granuloma annulare. $\mathrm{Br} J$ Dermatol. 1963;75(5):199-205.
9. Muhlemann MF, Williams DR. Localized granuloma annulare is associated with insulin-dependent diabetes mellitus. Br J Dermatol. 1984; 111(3):325-329.

10. Vázquez-López F, Pereiro M, Manjón Haces JA, et al. Localized granuloma annulare and autoimmune thyroiditis in adult women: a case-control study. J Am Acad Dermatol. 2003;48(4):517-520.

11. Wu W, Robinson-Bostom L, Kokkotou E, Jung H-Y, Kroumpouzos G. Dyslipidemia in granuloma annulare: a case-control study. Arch Dermatol. 2012;148(10):1131-1136.

12. Akyol M, Kiliçarslan H, Göze F, Emre S. Granuloma annulare associated with prostate carcinoma. J Eur Acad Dermatol Venereol. 2003; 17(4):464-465.

13. Barksdale SK, Perniciaro C, Halling KC, Strickler JG. Granuloma annulare in patients with malignant lymphoma: clinicopathologic study of thirteen new cases. J Am Acad Dermatol. 1994;31(1):42-48.

14. Winkelmann RK. The granuloma annulare phenotype and tuberculosis. J Am Acad Dermatol. 2002;46(6):948-952.

15. Yoon NY, Lee NR, Choi EH. Generalized granuloma annulare after bacillus Calmette-Guérin vaccination, clinically resembling papular tuberculid. J Dermatol. 2014;41(1):109-111.

16. Kakurai M, Kiyosawa T, Ohtsuki M, Nakagawa H. Multiple lesions of granuloma annulare following BCG vaccination: case report and review of the literature. Int J Dermatol. 2001;40(9):579-581.

17. Umbert P, Winkelmann RK. Histologic, ultrastructural and histochemical studies of granuloma annulare. Arch Dermatol. 1977;113(12): 1681-1686.

18. Spring P, Vernez M, Maniu C-M, Hohl D. Localized interstitial granuloma annulare induced by subcutaneous injections for desensitization. Dermatol Online J. 2013;19(6):18572.

19. Fulghum DD. Octopus bite resulting in granuloma annulare. South Med J. 1986;79(11):1434-1436.

20. Strahan JE, Cohen JL, Chorny JA. Granuloma annulare as a complication of mesotherapy: a case report. Dermatol Surg. 2008;34(6):836-838.

21. Gass JK, Todd PM, Rytina E. Generalized granuloma annulare in a photosensitive distribution resolving with scarring and milia formation. Clin Exp Dermatol. 2009;34(5):e53-e55.

22. Fayyazi A, Schweyer S, Eichmeyer B, et al. Expression of IFNgamma, coexpression of TNFalpha and matrix metalloproteinases and apoptosis of T lymphocytes and macrophages in granuloma annulare. Arch Dermatol Res. 2000;292(8):384-390.

23. Mempel M, Musette P, Flageul B, et al. T-cell receptor repertoire and cytokine pattern in granuloma annulare: defining a particular type of cutaneous granulomatous inflammation. J Invest Dermatol. 2002;118(6): 957-966.

24. Keimig EL. Granuloma annulare. Dermatol Clin. 2015;33(3):315-329.

25. Studer EM, Calza AM, Saurat JH. Precipitating factors and associated diseases in 84 patients with granuloma annulare: a retrospective study. Dermatology. 1996;193(4):364-368.

26. Kidd GS, Graff GE, Davies BF, McDermott MT, Aeling JL, Hofeldt FD. Glucose tolerance in granuloma annulare. Diabetes Care. 1985;8(4): 380-384.

27. Nebesio CL, Lewis C, Chuang T-Y. Lack of an association between granuloma annulare and type 2 diabetes mellitus. Br J Dermatol. 2002; 146(1):122-124.

28. Dicken CH, Carrington SG, Winkelmann RK. Generalized granuloma annulare. Arch Dermatol. 1969;99(5):556-563.

29. Binazzi M, Simonetti S, Simonetti V. Granuloma annulare, necrobiosis lipoidica, and diabetic disease. Int J Dermatol. 1988;27(8):576-579.

30. Davison JE, Davies A, Moss C, Kirk JMW, Taibjee SM, Agwu JC. Links between granuloma annulare, necrobiosis lipoidica diabeticorum and childhood diabetes: a matter of time? Pediatr Dermatol. 2010;27(2):178-181. 


\section{Publish your work in this journal}

Clinical, Cosmetic and Investigational Dermatology is an international, peer-reviewed, open access, online journal that focuses on the latest clinical and experimental research in all aspects of skin disease and cosmetic interventions. This journal is included on PubMed. The manuscript management system is completely online and includes a very quick and fair peer-review system, which is all easy to use. Visit http://www.dovepress.com/testimonials.php to read real quotes from published authors

Submit your manuscript here: https://www.dovepress.com/clinical-cosmetic-and-investigational-dermatology-journal 